\title{
Conexões entre Cultura Nacional, Identidade Corporativa e Marketing Global nas Empresas Americanas
}

\author{
Connections Among National Culture, Corporate Identity And Global Marketing In \\ American Companies
}

\author{
Jonas Abreu
}

Faculdade Anhanguera. RJ, Brasil.

E-mail: jonasabreu91@yahoo.com.br

\begin{abstract}
Resumo
Este artigo tem por objetivo analisar a correlação entre o processo de desenvolvimento dos valores que configuraram a cultura nacional dos EUA e as identidades corporativas das grandes empresas americanas. Como este fenômeno foi gerado nas empresas de sociedade anônima, mais livres das amarras governamentais, formou-se uma estrutura de mercado global liderado pelas corporações americanas, ao redor dos paradigmas científicos surgidos no século XX. A maioria gozava dos princípios de liberdade e igualdade, garantidos pela autorregulamentação da economia. A metodologia utilizada para obter os resultados desta problematização, se constituiu de pesquisa exploratória caracterizada pela investigação dos marcos históricos, antropológicos e sociológicos relacionados à cultura e identidade, bem como sua reprodução no ambiente empresarial. A pesquisa bibliográfica explorou autores como: Emile Durkheim, George Mead, Claude Lévi-Strauss, Franz Boas, Nestor Canclini, Denis Cuche, Pierre Bourdieu, Frederick Taylor, Renato Ortiz, Arthur Schlesinger Jr e Philip Kotler. Dados e infográficos foram obtidos em publicações econômicas e artigos de websites especializados. A pesquisa permitiu concluir que as tendências liberal e conservadora, que se alternam na história americana, definem o nível de envolvimento das corporações do país, observando tanto as inclinações mercadológicas quanto os Governos. Nessa combinação de fenômenos se verifica a empresa americana ser construída, inicialmente, em volta da teoria do laissez-faire e tornar-se modelo internacional por meio dos princípios da administração científica. Posteriormente, adaptou-se ao New Deal, encaminhou sua identidade para uma empresa do tipo global e por fim, atualmente, se experimenta certo declínio de sua influência em função dos mercados transnacionais que estão sendo configurados desde 1980.
\end{abstract}

Palavras-chave: Cultura Nacional. Identidade Corporativa. Marketing Global. Cultura Nacional Americana. Empresas Americanas.

\begin{abstract}
This article aims to analyze the correlation between the values development process that shaped the national culture of the USA and the corporate identities of large American companies. As this phenomenon was generated in corporations, freer from government bonds, a global market structure led by American corporations was formed, around the scientific paradigms that emerged in the 20th century. The majority enjoyed the principles of freedom and equality, guaranteed by the economy self-regulation. The methodology used to obtain the results of this problematization, consisted of exploratory research characterized by the investigation of historical, anthropological and sociological landmarks related to culture and identity, as well as their reproduction in the business environment. The bibliographic research explored authors such as: Emile Durkheim, George Mead, Claude Lévi-Strauss, Franz Boas, Nestor Canclini, Denis Cuche, Pierre Bourdieu, Frederick Taylor, Renato Ortiz, Arthur Schlesinger Jr and Philip Kotler. Data and infographics were obtained from economic publications and articles from specialized websites. The research concluded that the liberal and conservative tendencies, which alternate in American history, define the level of involvement of the country's corporations, observing both the market inclinations and the governments. In this combination of events, we saw the American company being built initially around the theory of laissez-faire and becoming an international model through the principles of scientific management. Subsequently, he adapted to the New Deal, forwarded his identity to a global company and finally, he currently experiences a certain decline in his influence because of the transnational markets that have been configured since 1980.
\end{abstract}

Keywords: National Culture; Corporative Identity. Global Marketing. American National Culture. American Companies.

\section{Introdução}

Os termos "cultura" e "identidade" devem ser examinados antes de se iniciar a trajetória de significados que colocará dentro das empresas americanas. Ambos os conceitos podem ser estabelecidos como uma ponte para se compreender o modelo de construção da "cultura nacional" dos EUA e de que forma foram elaborados e promovidos os símbolos caracterizadores da identidade corporativa das empresas americanas.
Por outro lado, as noções de identidade corporativa ou cultura de empresa não são próprias das Ciências Sociais. Sendo originárias do mundo empresarial, a partir das últimas décadas do século XX, incentivaram a discussão sobre os diversos temas da cultura e sua importância no âmbito corporativo. $\mathrm{O}$ pano de fundo desta discussão é o questionamento a respeito do alinhamento entre as estratégias de marketing global das grandes empresas de matriz americana e a cultura nacional dos EUA.

Optou-se por compreender as formas desta apropriação 
simbólica nas mais arrojadas empresas americanas, porque este país se consolidou como líder global, suas organizações contribuem com US 21 trilhões do PIB mundial ${ }^{1}$ e os seus princípios de gerenciamento são representados por modelos que influenciam vários executivos na busca por um protótipo de cultura que caiba nos formatos organizacionais de seus negócios. Como os conceitos de identidade corporativa e cultura empresarial foram se incorporando ao vocabulário das escolas superiores de administração e negócios, o artigo não visa contestar esta vinculação, nem pretende comprovar alguma nova teoria a respeito, mas compreender de que modo os termos e preceitos dos diversos usos da cultura nacional foram sendo entronizados no ecossistema empresarial americano.

Quanto à apuração dos resultados parametrizados nos EUA, houve duas fases: nos anos anteriores à I Guerra Mundial as práticas de apropriação das empresas na formação de uma identidade corporativa visavam ao estabelecimento de certa autonomia gerencial em relação aos governos, especialmente, com o advento da sociedade anônima e da prática do laissezfaire. Na fase seguinte, a partir dos anos 1910, caminhou-se para o estabelecimento de teorias fundadoras que remeteram a grupos de adesão nas empresas comprometidas com os valores comuns da cultura da nação. Propõe-se o termo "identidade corporativa" para trabalhar o discurso que as empresas fazem de si mesmas, o qual corresponde também à manifestação da estrutura cultural do país que vinha sendo elaborada concomitantemente.

Para identificar esse arranjo foram definidos os objetivos: distinguir antropológica e sociologicamente a evolução dos conceitos de cultura, cultura de empresa e identidade corporativa, observar os seus usos no ambiente empresarial, discutir o impacto da cultura nacional nas identidades das empresas americanas e analisar o marketing global como recurso estratégico e publicitário dos modelos de negócios originados nos EUA.

\section{Desenvolvimento}

\subsection{Metodologia}

Durante a composição das pesquisas, foram consultados livros e artigos de antropólogos, cientistas sociais e historiadores que relataram ou discutiram a estrutura conceptiva da cultura. Foi possível captar de sociólogos uma avaliação a respeito da cultura empresarial como noção analítica, mas também os prováveis usos deste termo para manipulação ideológica. Pesquisadores de marketing contribuíram com seus estudos mercadológicos no âmbito do conceito de identidade corporativa e marketing global.

A metodologia se concentrou em pesquisa exploratória, valendo-se de dispositivos de consulta bibliográfica e eletrônica em websites. Assim foi possível cumprir o propósito de sair em busca de padrões de acúmulo simbólico nas relações associativas estabelecidas local e globalmente por estas organizações, procurar ideias conflitantes ou descobrir hipóteses sobre como o modelo da grande empresa aberta americana foi assimilado ou rejeitado e em quais circunstâncias.

O artigo está dividido em três seções. Inicialmente, foram traçadas a trajetória da abordagem antropológica e sociológica de cultura e identidade, possibilitando que os estudos sobre cultura empresarial, por exemplo, fossem relativizados e contemplados sob a ótica de microculturas em torno da empresa. Na segunda seção foi possível descrever o impacto dos valores nacionais constitutivos da nação sobre as corporações e de que modo as empresas americanas os incorporaram em suas identidades corporativas. Na terceira seção houve a preocupação de descrever alguns paradigmas de administração e marketing identificados no ambiente competitivo dos EUA e sua capacidade de influenciar os modelos culturais e gerenciais em termos globais.

\subsection{Pistas a partir das abordagens antropológicas e sociológicas, sobre cultura e identidade}

A noção de cultura é necessária para pensar a diferença entre os povos, as entidades, os governos e as empresas. A legitimação do uso da palavra "cultura" nos termos que interessam foi sendo construída desde o Iluminismo. Dois fundamentos prevaleceram: a lógica simbólica do universalismo francês e o nacionalismo alemão. Ambos acirraram o debate sobre o significado da palavra e a partir de seus modelos a cultura foi pensada nas Ciências Sociais. O debate franco-alemão segue como parâmetro das concepções básicas sobre cultura nos séculos XVIII e XIX até a contribuição da antropologia americana no século XX.

Nesta trajetória pelo direito de definir o conceito de cultura, na França do século XVIII, os pensadores do Iluminismo concebem a cultura como uma característica distintiva da espécie humana, o resultado da soma dos saberes. A noção de universalidade integrada à cultura é justificada, uma vez que a palavra se associa às ideias de progresso, de evolução, de educação e de razão, próprias do ideal revolucionário francês e da doutrina iluminista surgida na Inglaterra (CUCHE, 2002). O autor lembra que é a palavra "civilização" mais que "cultura" que vai fazer parte do vocabulário francês nesta época. "Cultura" invoca os progressos individuais enquanto "civilização" associa os progressos coletivos da humanidade. Os filósofos franceses defendiam a ideia de que a civilização deveria se estender a todos os povos, desde que a partir do modo como a França se via: civilizada e progressista.

Segundo Cuche, na Alemanha do século XVIII, embora a palavra Kultur seja homóloga ao sentido que se desenvolveu na França, apresenta-se sob um enfoque singular. Ao contrário da França, há um maior distanciamento entre a aristocracia e

1 Dado consultado junto à publicação da lista de PIBs da Trading Economics, 2019. 
a burguesia alemã, o que permite que esta última desenvolva o conceito de cultura como enriquecimento intelectual, uma vez que os aristocratas por conceber a maior parte do seu tempo ao cerimonial da corte imitando os modos franceses "civilizados", seriam considerados supérfluos (CUCHE, 2002). A intelectualidade alemã vai usar esta marca distintiva da cultura de sua classe para conduzir a unificação alemã no século XIX, em oposição ao conceito humanista francês. Politicamente, isso significa que a noção alemã de Kultur delimita as diferenças nacionais da Alemanha como nação, opondo-se ao conceito francês universalista de "civilização".

Nos EUA, designadas a partir de experiências de campo como as de Franz Boas, uma certa concepção particularista de cultura aparece, influenciada pelo aforismo alemão, para pensar as diferenças em oposição às totalidades nacionais ou universais (CUCHE, 2002). Uma significativa parte dos estudos de Boas (1932) se inclinou para romper com a noção de raça proveniente das supostas ligações entre traços físicos e mentais, uma teoria muito em voga e aceita no início do século XX. Para ele, as chances de serem elaboradas leis universais para o funcionamento das sociedades e das culturas humanas ou uma teoria que explicasse a evolução da cultura eram mínimas. Defendeu com veemência em um célebre discurso $^{2}$, a interdependência dos fenômenos culturais como o verdadeiro objetivo da pesquisa antropológica, reforçando invenções, vida econômica, estrutura social, arte religião e moral estão inter-relacionadas, contribuindo para relativizar o etnocentrismo europeu.

Depois dos estudos americanos que, de certa forma, reposicionaram os conceitos de cultura elaborados na França, tem-se em Lévi-Strauss a retomada do pensamento da totalidade cultural. Sua análise estrutural da cultura está amparada na realidade físico-social que sustenta relações simbólicas nas diversas culturas. No capítulo "Raça e Cultura" de sua famosa obra "Raça e História" (1952), ele enxerga a humanidade se desenvolvendo de maneira multiforme, diversificada em termos de sociedades e civilizações. Esta diversidade cultural e sociológica não está unificada por alguma relação de causa e efeito no plano biológico, contudo se desenvolve paralelamente a outro terreno, ou seja, o da cultura. Haveria mais culturas humanas do que raças humanas. Ele encaminha o argumento de que se não existem aptidões raciais inatas, como explicar que a civilização desenvolvida pelo homem branco tenha feito os imensos progressos que se conhece, enquanto as dos povos de cor permaneceram atrasadas, umas a meio do caminho e outras atingidas por um atraso que se cifra em milhares ou dezenas de milhares de anos? Lévi-Strauss sustenta que não se pode pretender ter resolvido, negativamente, o problema da desigualdade das raças humanas, se não se debruçar também sobre o da desigualdade - ou da diversidade - das culturas humanas que, de fato, senão de direito, está com esse estreitamente relacionado, no espírito do público (LÉVI-STRAUSS, 2009).

Entre os autores de natureza universalista se destacam, ainda, Durkheim (1990) que defende a abordagem unitária dos fatos da cultura, os quais admite ser uma característica universal, e ainda que comporte pluralidades, sendo admitida como um fator incentivador da civilização. Em seu famoso artigo, "Algumas formas primitivas de classificação" dividido com Marcel Mauss em 1902, ele admitia que os "primitivos" estariam inequivocamente aptos ao pensamento lógico. Contrário às teses individualistas do psicologismo, Durkheim afirmava a prioridade da sociedade sobre o indivíduo, tendo desenvolvido a teoria da consciência coletiva que não deixa de ser uma teoria cultural. A consciência coletiva precederia o indivíduo, pois seria resultado das crenças, valores e juízos de todos os sujeitos de um grupo social. (DURKHEIM, 1990).

A análise da obra do sociólogo francês Pierre Bourdieu (1983) é essencial aqui, por causa da noção de habitus que ele apresenta sob a forma de estruturas estruturadas e estruturantes capazes de funcionar ainda que inconscientemente, como princípios geradores e organizadores de práticas culturais e de representações sociais hierarquizadas. Segundo Bourdieu (1983, p. 91-95), as pessoas funcionam dentro de campos simbólicos, nos quais vários agentes se encontram em posição de dominados ou dominantes, enquanto buscam legitimidade e reconhecimento no campo. Quem acumula conhecimento se torna dominante e pode instrumentalizar o campo, direcionando a doxa, isto é, as regras e verdades implícitas, que são conhecidas dos dominantes do campo. A doxa pode ser atualizada pelos novos dominantes à medida que estes avancem no domínio dos objetivos em comum do campo e ao mesmo tempo influenciem os valores simbólicos a serem alcançados. Bourdieu (1983, p.94) descreve o conceito de habitus neste contexto:

habitus, sistema de disposições adquiridas pela aprendizagem implícita ou explícita que funciona como um sistema de esquemas geradores, é gerador de estratégias que podem ser objetivamente afins aos interesses objetivos de seus autores sem terem sido expressamente concebidas para este fim.

Os arranjos mentais elaborados nos campos simbólicos teriam o poder de direcionar as apreensões do mundo social aos indivíduos que se encontram interiorizados ou sob a influência do campo. O habitus integra as experiências passadas, mas sendo produto da história deve ser interpretado como um sistema aberto de representações confrontado e afetado com novas simbologias, portanto durável, mas não imutável.

Quanto ao termo identidade, parte-se da premissa de autores como Kaufmann (2004), que adverte que o conceito de identidade é inerente à modernidade, uma vez que o indivíduo coexistindo nas sociedades tradicionais não conseguia perceber a si mesmo como um indivíduo em

2 Conferência proferida em Atlantic City, 1932, no encontro da American Association for the Advancement of Science, quando entregava o cargo de presidente. 
particular, gozando plenamente de suas prerrogativas de sujeito. Como não tinha ciência das questões que envolvia sua própria identidade, esta era encapsulada pelo grupo social a qual pertencia. Uma conceituação mais nitidamente de caráter sociológico surgiu remontando à tradição da Escola de Interacionismo Simbólico, por meio da obra do filósofo George Herbert Mead (1993), que tinha como um de seus interesses de pesquisa a relação entre a mente, o self e a sociedade. O autor observa que não existe a construção do "eu" sem atentar para a interação com os outros. Assim, dividida entre o sujeito iluminista, consciente de sua identidade e seu valor individual e o sujeito sociológico, absorvido pela conjuntura social, a visão antropológica da identidade caminha para percebê-la como um conjunto de signos, referências e motivações que delimitam a compreensão das relações de uma determinada entidade, percebidas em seus contrastes, isto é, pelas diferenças entre essas. Desse modo, identidade está relacionada à ideia da alteridade, da existência do outro para que determinado sujeito se posicione pela comparação.

Algumas identidades de grupo têm sido partilhadas, nos últimos anos, como acontece com as identidades nacionais. Deve-se considerar este sentido de pertencimento ligado a fatores étnicos, mitos de origem, histórias de conquistas ou consensos ideológicos. As pessoas que vivem sob certos padrões religiosos ou normas sociais igualmente tendem a formar um grupo com uma identidade nacional.

O debate prossegue quando os estudos de cultura e identidade frequentam outros campos semânticos e surgem categorias temáticas simplistas como "cultura empresarial", "identidade corporativa" e "marketing institucional" que já se introduziram neste novo fenômeno linguístico atual globalizado. Destes termos se tratará a partir de agora.

Seria interessante visitar novamente Denis Cuche (2002), que analisa o surgimento do termo "cultura de empresas" e seu uso na linguagem empresarial. O autor relata que a expressão apareceu, pela primeira vez, nas empresas americanas durante os anos 1970, no contexto da concorrência com os japoneses e na busca por uma forma de mobilizar seus empregados. Posteriormente, na França, durante a década de 1980 vai aparecer nos discursos dos responsáveis pelo gerenciamento. $\mathrm{Na}$ busca por uma ênfase humana nos fatores de produção, os gestores empresariais teriam feito uso da noção antropológica de cultura com o propósito de obter certos níveis de adesão aos seus objetivos empresariais previamente definidos (CUCHE, 2002).

A interpretação culturalista retirada da antropologia pelos empresários circunscrevia a cultura como dominadora dos sentidos do indivíduo situando as empresas como "tribos", significativamente autônomas, a ponto de solapar as individualidades de seus colaboradores. Torna-se desnecessário reforçar que este conceito de cultura abandonado pelos antropólogos, foi na verdade retomado como um argumento para se poder manipular, ideologicamente, a lógica do trabalho e do ambiente organizacional.
A unicidade que este termo parece demonstrar, na verdade, requer que seja reavaliada. A empresa pode se ver como produtora de sistemas culturais, que estejam afinados com a sua proposta estratégica, mas também é verdade que a cultura de empresa não deve ser vista como proveniente da Administração ou fruto de uma linguagem gerencial. Observando os estudos centrados nos procedimentos de controle elaborados por Foucault (1996) e os princípios deterministas do habitus de Bourdieu (1983), pode-se concluir que o discurso da cultura corporativa parece ter sido imposto aos empregados, em detrimento da cultura "real" vivenciada nas empresas, como resultado do complexo jogo de interações internas.

O sociólogo Renaud Sainsaulieu (1997) se notabilizou pelos seus estudos relacionados à cultura e à construção da identidade social e individual nas empresas. Ele salienta que quando há uma ampliação da corporação na busca por um portfólio mais diversificado de seus produtos e tecnologias, difusão de sua rede de fornecedores e clientes e uma consequente expansão geográfica de sua malha de negócios, o problema de racionalidade, com o qual a organização passa a lidar não está mais circunscrito somente às operações particulares da tarefa de produção.

Desse modo, a visão sociológica sobre a cultura de empresas parece dar conta do exame mais minucioso requerido para a análise deste sistema, pois é usada para identificar o resultado das confrontações culturais entre os diversos grupos sociais incluídos em uma corporação. Alguns estudos anteriores já haviam demonstrado que os trabalhadores não chegam despidos de cultura nas organizações. Eles trazem sua vivência operária, técnica e gerencial de outras empresas, seus valores de classe ou mesmo as crenças internalizadas nos campos simbólicos do qual participam (igrejas, clubes e famílias). A cultura de uma empresa é, na verdade, um produto da interseção entre as microculturas de grupo.

A experiência americana, entretanto, se organizou mais eficazmente que todas as nações industriais da Europa para diminuir a vocalização destas categorias internas, por meio das apropriações feitas pelos seus gestores sobre quais valores das organizações deveriam ser externalizados em detrimento da percepção que os microgrupos internos faziam da identidade da organização. Isso confirma a opção por examinar esse fenômeno como um processo de concepção da "identidade corporativa", mas não de "cultura empresarial", uma vez que a cultura das organizações é o somatório das culturas de grupo que interagem a partir de suas próprias crenças e juízos na mesma empresa. Utiliza-se o termo "identidade corporativa" ao invés de "cultura de empresa", no sentido de salvaguardar a ideia de uma proposta da empresa sobre como essa quer ser percebida, mas sem as garantias de que a imagem percebida corresponda ao pretendido. 


\subsection{A cultura nacional americana forja as identidades corporativas e impacta a rede de negócios internacional}

A identidade corporativa como proposta da empresa precisa levar em conta o ambiente que a cerca. Se considerar a identidade corporativa um projeto autônomo, delineado pelos executivos se nega a influência da economia e do mercado, além de abstrair o impacto das culturas nacionais sobre as identidades organizacionais.

Para situar os efeitos da cultura nacional americana nas empresas globais originadas neste país, precisa-se delinear a formação dos símbolos marcadores da nação, vale dizer, a "alma da América", como preferem alguns historiadores. A história da democracia americana incluiu a luta pela liberdade política, religiosa e econômica e ganhou excepcional fascínio na expansão para o Oeste. A interpretação original teceu a ideia de uma história de oportunidade e experimento democrático, que considerava os EUA e todas as comunidades seculares finitas e problemáticas, a partir do princípio de que floresciam e entravam em decadência. Durante a revolução que consolidou a separação das colônias americanas da GrãBretanha, os ideais iluministas e deístas colocavam a razão em primeiro lugar, seguindo os princípios de John Locke ${ }^{3}$ de que os homens, em seu estado natural, nasciam "iguais e independentes". Talvez, o marco histórico deflagrador do experimento dos Estados Unidos da América como nação democrática por excelência tenha sido capturado com rara proeminência por James Davidson (2016), quando descreveu a vitória do Exército Continental que havia virado os britânicos de cabeça para baixo, em 1781.

O Exército Continental foi onde os Estados Unidos experimentaram, pela primeira vez, um sentimento de unidade. De muitos, um. Eles eram velhos de 60, rapazes de 14 e negros de todas as idades, e maltrapilhos em sua maioria. Relatou um oficial britânico, torcendo o nariz. [...]. Mas esses continentais passaram a se ver como iguais a qualquer pessoa.

E travaram uma guerra longa e dura o bastante para tornar a si mesmos, e à sua nova nação, totalmente independentes (DAVIDSON, 2016, p. 91).

Este fio condutor não permaneceu unânime. Um segundo alicerce começou a ser estruturado assim que a missão dos fundadores foi cumprida com a independência das colônias. De fato, a "experiência democrática" foi cedendo lugar ao "destino manifesto" como argumento da vida nacional. A teoria teria ganhado corpo após a independência, porque um novo status para a América começou a ser elaborado, passando a ser vista por alguns formadores de opinião e autoridades eclesiásticas como "nação eleita", embora não houvesse aspectos materializadores que evidenciassem o protagonismo deste fenômeno. Analisando a democracia americana, Arthur Ekirch Junior (1965, p.104) assinalou este marco histórico:

Em contraste com a época da Revolução americana, quando parecia que o cristianismo corria o perigo de ser secularizado pelo novo nacionalismo americano, agora parecia haver alguma perspectiva de que o protestantismo evangélico dominaria a nova ordem democrática.

Acompanhando este raciocínio, Schlesinger Jr (1992) confirma que a ideia do experimento democrático foi ganhando novas interpretações, embora o conceito de "destino manifesto" não tenha sido cristalizado antes da década de 1840. Um dos mais famosos líderes religiosos da época, o Rev. Josiah Strong, por exemplo, defendia que os hebreus, os gregos e os romanos, vistos como fonte de inspiração pelos fundadores, teriam desenvolvido separadamente as qualidades espirituais, intelectuais e físicas do homem para desembocar em uma só e suprema civilização na nova era. Essa raça única seria a anglo-saxônica, escolhida por Deus para preparar o caminho para a realização de seu reino na Terra. Este fervor patriótico, que muito além dos limites da comunidade evangélica, subscreviam os americanos como um povo eleito, incumbido de uma missão divina de redimir os povos e servir de padrão ético e político para as nações. Em meio a essa abordagem, alguns historiadores trabalharam a ideia da saga americana dividida em ciclos progressistas ou conservadores.

Arthur Meier Schlesinger, cuja primeira versão de seu argumento "Tides of American Politics", publicada na Yale Review, em 1939, e sua revisão em Paths to the present (1949), apontava para uma interpretação deste fenômeno, pois trabalhava a ideia de uma oscilação entre conservantismo e liberalismo. Seu filho, Arthur Schlesinger Junior, na obra "Os ciclos da história americana" (1992), afirma que o pai prescreveu no ensaio de 1949 o seu quebra-cabeça: defendia que a política americana ocorria em meio a um rodízio entre dois períodos definidos: preocupação com os "direitos das minorias" separados por intervalos de "preocupação com os erros da maioria" (SCHLESINGER JR, 1992). Estes ciclos começariam com os Governos dos fundadores da nova República: George Washington e John Adams e as agitações de Thomas Jefferson, seguindo-se alternadamente períodos conservadores e liberais a partir da retirada jeffersoniana com a guerra de 1812 e seguem até a década de 1970 (SCHLESINGER JR, 1992). As projeções de Schlesinger se encerram com o período liberal do Governo Kennedy dos anos 1960 que ele projetava para até 1978. Como morreu em 1965 , se poderia seguir suas pegadas e chegar à conclusão de que o novo quartel conservador iria ocupar o período 19781993. De fato, após Ronald Reagan e George H.W. Bush tem início a temporada liberal de Bill Clinton (1993-2001), o que permite ajustar, hipoteticamente, os mandatos presidenciais e os partidos majoritários como se fossem ciclos. Assim, a nova rota conservadora militar do republicano George Bush (20012009) foi seguida pelo Governo democrata de Barack Obama

3 John Locke é conhecido como o "pai do Iluminismo". Na obra "Ensaio sobre o entendimento humano" ele defende a razão afirmando que a nossa mente é uma tábula rasa sem nenhuma ideia. Defendeu a liberdade individual dos cidadãos, confrontando a autoridade absolutista. Fonte: sohistoria. com.br 
(2009-2017) e da nova "onda" conservadora republicana iniciada com Donald Trump em 2017.

Ao longo desta trajetória, as palavras "capitalismo" e "democracia" aparecem como intrínsecas na formação da América. Como valores ligados à democracia se encontrar igualdade, liberdade, responsabilidade e bem-estar social, tudo regulamentado pelo Poder Público e com alguma restrição ao lucro. Por outro lado, pode-se fazer a melhor associação do capitalismo com os valores que forjaram a identidade americana: o preceito da propriedade privada, a maximização do lucro, o culto ao livre mercado e a sobrevivência do mais preparado. Desse modo, embora capitalismo e democracia sejam faces da mesma moeda e tenham compartilhado na história americana, os mesmos ideais de revolução contra a monarquia e confirmassem a fé na liberdade individual, os dois credos apostaram em direções diferentes quando se observa o percurso dos ciclos.

De que forma esses valores nacionais foram evidenciados nas identidades das empresas americanas? Poderia se comparar outros sistemas empresariais e suas relações com os paradigmas culturais de seus países de origem?

O exemplo mais emblemático envolve o modelo japonês de gerenciamento, que foi estudado, incansavelmente, durante os anos 1970, tendo sido considerado um paradigma universal. Keys e Miller (1984) se referem a estes estudos como a "selva da teoria gerencial japonesa" - título de seu livro a respeito, o que chama a atenção para uma renovada literatura que está sendo revisada até hoje, sendo genérica qualquer tentativa de levantamento bibliográfico definitivo.

Em um estudo bibliográfico feito em 1990 na EAESP/FGV, os pesquisadores já sinalizavam que era "comum encontrar na literatura a ideia de que as práticas gerenciais japonesas são produtos únicos da cultura e história japonesa" (SUGO; VASCONCELLOS, 1990) $)^{4}$. Segundo os autores, isso poderia conduzir os estudiosos a negarem o sucesso da transferência das receitas gerenciais japonesas para os demais países.

Na China, até os anos 1980, o desempenho das empresas era vinculado aos planos estatais do Partido Comunista. Hofstede e Bond (1988) relatam a importância da tradição confucionista no gerenciamento das empresas chinesas, fundamentado nas relações de equilíbrio e conformismo. Nesse aspecto, ainda prevalece nas corporações chinesas a lógica dialética em detrimento da lógica formal, seguida nas empresas americanas e europeias. Seguindo este raciocínio algumas características são encontradas nos gerentes chineses: menos preocupação com os prazos, práticas corporativas socializadoras de benefícios mútuos aos parceiros e tendência ao corporativismo funcional.

No caso dos EUA, existe uma complexidade que precisa ser analisada historicamente. Na nascente estrutura de mercado, após a independência, prevaleceram inicialmente os postulados que seriam defendidos por Thomas Jefferson, o terceiro presidente americano (1801-1809). Estes princípios, segundo Tucker e Hendrickson (1992), foram construídos por meio da promoção dos ideais do republicanismo, que demonstrava a visão de Jefferson de um país como o grande "Império de Liberdade", promotor da república em contraposição ao imperialismo monárquico britânico. Idealizava as fazendas como um exemplo da virtude empreendedora republicana, ao mesmo tempo em que desconfiava das cidades e do setor financeiro. Schlesinger Jr (1992) afirma que ele questionava a autoridade federal na economia e na vida dos cidadãos, mas tolerava as intervenções rotineiras em nome da prudência nacional, configurando um tipo de cooperação entre o Poder Público e Privado necessários naquele momento histórico de construção do país.

Nessa trajetória de acúmulo simbólico se vê a economia americana abrir seus caminhos, especialmente, após a década de 1830, quando as empresas iniciaram um período de autossustentabilidade, que não tinha sido visto antes. Segundo Schlesinger Jr (1992), o crescimento das sociedades anônimas privadas ocorreu paralelamente ao declínio da empresa pública, assegurando à comunidade comercial um período de robusto crescimento econômico observando os seus termos em detrimento da capacidade do Estado de usálas em seu próprio interesse. A necessidade ideológica estava condicionada a fazer a América segura para as corporações privadas, mais capazes de focar na produção e inovação e menos na construção da infraestrutura. A publicidade em torno deste enunciado era sintetizada por meio das tradições de origem da nação. O autor percebia a engrenagem espaçotemporal, que envolvia o estilo das empresas americanas e sua relação com o ecossistema político do país.

A América do século XVIII era um país de capital limitado, e a política econômica não viu alternativa senão conjugar energias públicas e privadas. Depois, por um tempo estonteante, no fim do século XIX e começo do século XX, a América pareceu um país de possibilidades ilimitadas. Nesses anos, políticas nacionais emergiam do conflito - o Norte contra o Sul, as cidades contra o campo, a classe trabalhadora contra os capitalistas, os americanos natos contra os imigrantes, os brancos contra os pretos, o indivíduo contra o Estado (SCHLESINGER JR, 1992, p. 286).

Esta conjuntura teria permitido a fixação do mito laissezfaire no desenvolvimento econômico americano, a partir dos anos 1860. Todos viam a América como o país da empresa privada por excelência, o local no qual a interferência do Estado foi a menor possível, separando para as empresas individuais as maiores oportunidades. A sensação que se construiu no fim do século XIX é que tinha sido sempre assim. Esse cenário trouxe, para o palco do século XX, as experiências de algumas corporações empresariais americanas como Coca-Cola, Ford e General Electric, ao lado dos seus fundadores ou ícones principais: John Pemberton, Henry Ford e Jack Welch. Todavia, na empresa global que começava a

4 A pesquisa foi realizada no acervo da Biblioteca da EAESP/FGV e publicada no website da Scielo (Electronic Library Online). 
dar seus primeiros passos, no mercado americano, havia uma gênese altamente desenvolvida daquilo que seria justificado a partir da década de 1910 pelas Teorias da Administração, elaboradas por figuras ilustres que construiriam os arquétipos das técnicas de produção, gerenciamento e comercialização modernas.

A partir de Frederick Taylor se organizou um sistema de trabalho elaborado com o objetivo de alcançar o máximo de produção e rendimento com o mínimo de tempo e de esforço. A publicação de seu livro "Princípios de Administração Científica" (1911) rompe, ainda que parcialmente, as estruturas da empresa tradicional americana, uma vez que ele propõe demonstrar que a administração de uma corporação não deve ser empírica, confiada a "homens melhores e mais capazes", que construiriam as bases de sucesso de um negócio a partir de sua visão, como ocorreu com os fundadores da Coca ou GE, mas a profissionais que viessem preparados por eles.

No passado, a ideia predominante era expressa nesta frase - os chefes das indústrias nascem, não se fazem - e daí a teoria de que tendo se encontrado o homem adequado para o lugar, os métodos deveriam ser a ele, incondicionalmente confiados. No futuro prevalecerá a ideia de que nossos líderes devem ser tão bem treinados como bem-nascidos e que nenhum homem, embora excelente, sob o antigo sistema de administração de pessoal, poderá competir com homens comuns, mas organizados, adequada e eficientemente para cooperar (TAYLOR, 1990, p.22).

A ideia principal do livro é a racionalização do trabalho, que envolve a divisão de funções dos trabalhadores. O texto inclui partes de uma fala do presidente Theodore Roosevelt (1901-1908), que retrata a sua inconformidade com a “eficiência nacional” severamente abalada pela destruição das florestas, o desperdício das forças hidráulicas e do provável esgotamento das minas de carvão e ferro. O presidente, entretanto, enfatiza que isso seria efeito do desgaste dos esforços humanos originados em atos errôneos, mal gerenciados ou ineficientes. Chama a atenção que este apelo do presidente aos governadores reunidos na Casa Branca, soa como uma convocação às forças industriais dos EUA:

Até agora, não houve nenhum movimento em favor da maior eficiência nacional, nem reuniões foram convocadas para discutir como tal questão deve ser estudada e, contudo, há sinais de que é vivamente sentida a necessidade desta maior eficiência (TAYLOR, 1990, p.21-22).

Roosevelt imaginava uma Nação que evitasse os prejuízos diários e investisse em cooperação sistemática para treinamento e qualificação de pessoas. A importância desse fator resultava em uma ênfase menor nos desperdícios das coisas materiais. Se uma nação pode ser assim imaginada, essa pode trazer também implicações na forma como as empresas constroem suas identidades corporativas.

Não seria equivocado afirmar que a moderna Nação americana teria sido modelada dentro de suas empresas. Comentando sobre como uma Nação pode ser imaginada, Stuart Hall (2006) afirma que as culturas nacionais são compostas de instituições culturais, símbolos e representações.

Nesse sentido, funciona igualmente como um discurso, um modelo para se construir sentidos para as ações e para as crenças que a pessoa possui sobre si mesma. Este princípio deve ter impulsionado Taylor a construir não somente uma nova forma de administrar negócios, mas uma filosofia que deveria atuar na construção da identidade da América, em conformidade com o discurso de Roosevelt.

Se a identidade nacional é uma comunidade imaginada, como argumentou Benedict Anderson (1983), não é difícil compreender que nos EUA se tenham construído os valores concebidos pelas corporações originadas em suas terras, por meio do imaginário de sua identidade nacional. As estratégias representacionais utilizadas puderam acionar alguns dos signos, que compunham a formação da própria identidade da nação e as sensações de pertencimento dos indivíduos da nação: importância dos sistemas organizacionais, espírito do empreendedorismo explorando a direção racional e aplicação incondicional dos princípios científicos. Todos estes valores eram análogos às crenças vivenciadas nas colônias, quando elaboraram seu complexo sistema político e religioso. Continuaram após a Revolução Americana do século XVIII e ultrapassaram os limites impostos pela Guerra Civil da década de 1860 .

Taylor mantinha sua preocupação focada na Filosofia da Administração científica, que exigiria um recondicionamento mental da direção e dos operários no sentido de convergirem os seus objetivos para o bem comum, isto é, a prosperidade financeira de ambos, resolvendo seus antagonismos anteriores. Essa conjuntura pode motivar a entender os mecanismos pelos quais as empresas americanas impactadas pelas teorias e experimentos científicos da Administração, a partir dos anos 1920, difundiram seus valores para os meios de comunicação (redes de rádio, produções cinematográficas, jornais e publicações), além de Governos e entidades da sociedade civil. Suas mensagens evoluíram nas décadas seguintes com o apoio da TV para um caráter institucional, reproduzindo os aspectos da "cultura organizacional", que fossem relevantes e projetados pelos seus gestores.

Universidades reconhecidas, como Harvard, Yale, Stanford, Massachusetts Institute of Technology e Princeton University replicaram este discurso, despejando cases studies, papers e publicações sob a forma de compêndios teóricos, manuais e enciclopédias para dar conta das demonstrações sobre como as empresas americanas se tornaram paradigmas da Administração contemporânea. Evidentemente, não faltou nas publicações uma significativa parcela de contribuição sobre a "cultura empresarial".

Apesar de indiscutível, o poder que as grandes empresas começaram a dispor colocou em xeque a capacidade dos Estados de lidarem com a atividade econômica. Por isso, a tese do Governo afirmativo cresceu à medida que a necessidade de intervenção federal na economia liberal foi formulada, mas o discurso da empresa autônoma preparada 
para andar sob a régua de um corpo diretor e preocupada em direcionar os negócios, de forma independente dos Governos, continuou prosperando. A imagem corporativa resultante deste posicionamento não foi eliminada nem mesmo com o crash da Bolsa de New York, em 1929. É verdade que certo nível de desconfiança se instalou na estrutura liberal da economia americana, por conta das ideias progressistas subsequentes à depressão econômica e pelo New Deal da era Franklin Roosevelt, posterior a II Guerra.

O Estado se via agora como protetor dos excessos do poder econômico originados da atividade industrial das grandes corporações. A concepção associada a Jefferson via a América como uma paisagem de pequenas propriedades livres e seguras, enquanto a visão conservadora sobrevivente da I Guerra Mundial apontava para a desconfiança no laissez-faire e do mercado livre. Nenhum destes ideais acabou vingando isoladamente, mas a Democracia americana sustentada por uma massa cada vez maior de população urbana e imigrante decidiria pelo planejamento, como solução mais praticável, no século XX, do que o "agrarianismo" de Jefferson (EKIRCH JR, 1965). Na década de 1930, o espírito do planejamento, já iniciado pelos setores industriais e comerciais, desde as interpretações positivas do discurso científico do início do século, seria repassado para a sociedade.

As leis antitrustes eram a resposta de uma sociedade de grandes organizações e, ao mesmo tempo, tinha de negarlhes um lugar na ideologia moral e lógica da estrutura social. Faziam parte da luta de um credo de individualismo intransigente para adaptar-se ao que se estava convertendo numa sociedade altamente organizada (EKIRCH JR, 1965, p. 263).

Quando se olha para este quadro geral da sociedade americana até 1950 se pode aprender um pouco da Democracia de massas, que estava sendo modelada, desfigurando os ideais liberais individualistas do século XVIII, típicos da Democracia jeffersoniana em favor de políticas nacionais, isto é, um tipo de Governo afirmativo, capaz de humanizar a ordem industrial e atender às dificuldades crônicas da economia de mercado estabelecidas durante a depressão econômica e após a II Guerra Mundial.

\subsection{Discursos e táticas globais a serviço da imagem modernizadora das corporações americanas}

Em 1954, Peter Drucker lançou o livro The practice of Management (A Prática de Gestão), popularizando uma habilidade que parecia ser possível apenas aos gênios do empreendimento. Esta obra se tornou um marco histórico da Gestão Empresarial, tendo sido atribuído ao autor a utilização da palavra "marketing", aproximadamente, do modo como se entende hoje. Drucker reforçava aos administradores sobre a importância do marketing, identificado como uma ferramenta essencial para se conhecer o mercado.

Além de Peter Drucker, surge outra lenda, cujo livro Marketing Básico: uma visão gerencial (1960) tem sido a publicação de marketing mais vendida no Mundo. Tornou o seu autor, Jerome McCarthy, uma celebridade, com a criação do conceito dos quatro pês: produto, preço, praça e promoção, que compõem o composto de marketing. Sua teoria foi popularizada por Philip Kotler, o maior guru de estudos de mercado surgido nos EUA. Desde que começou a ministrar aulas de marketing, em 1962, na Kellogg School of Management, da Northwestern University se tornou um dos consultores mais prestigiados no campo da mercadologia.

Ambos defendiam uma ideia que se tornou midiática e que passou a representar o modelo de gerenciamento americano a ser exportado para o Mundo: o marketing era uma parte essencial da economia por conta de suas funções gerenciais básicas. Tanto a política de preços, como a publicidade, promoções, força de vendas e distribuição influenciariam as estratégias empresariais. Esses e outros autores relacionavam o lucro aos índices de satisfação do consumidor e com o bemestar da sociedade.

A aposta em uma filosofia empresarial cujo objetivo é produzir satisfações significativas aos consumidores, tendo como retaguarda um sistema de serviços integrados, invertia o conceito de vendas e fundamentava os princípios da identidade corporativa da empresa moderna que se pretendia para as corporações americanas. A aplicação das estratégias de marketing seria o meio pelo qual as empresas atingiriam suas metas organizacionais.

Assim como os gestores das corporações americanas perceberam, desde o Fordismo nos anos 1920, que as Teorias da Administração científica podiam estabelecer regras para o jogo da construção da identidade corporativa de suas empresas, a batalha nos anos 1950 havia sido ampliada, inaugurando uma nova simbologia poderosa e unificadora, focada no marketing de consumo e em planos de comunicação integrada.

Embora somente nos anos 1980 tenham surgido as Teorias de Marketing Institucional, que se descolam dos programas e ações ligados, tradicionalmente, à produção e comercialização para calcular os impactos de projetos sociais, ambientais e culturais na imagem das empresas, observa-se que o mito da empresa privada organizada e gerenciada racionalmente, massageava o ego dos seus presidentes e gestores, durante todo o percurso do século XX, realizando seus propósitos pessoais. $\mathrm{O}$ tema da filosofia do empresariado e a sua publicidade mantinham viva a fé na economia autorregulamentada.

Após a II Guerra Mundial várias empresas americanas consolidaram sua expansão internacional como CocaCola, Ford, Exxon, Mobil, Gillette e General Motors. Mais recentemente, McDonalds, Sears e Walmart. A Biblioteca do Congresso e as Universidades, tendo Harvard à frente, se tornaram centros irradiadores das ideias da cultura, da eficiência empreendedora e da produtividade, ao mesmo tempo em que combatiam as ideologias e preconceitos contra os Estados Unidos. A produção de conteúdo alinhado com os valores americanos se infiltrou em órgãos de comunicação, 
entidades de ensino e instituições governamentais.

Ainda que Peter Drucker tenha determinado como um dos credos de marketing que as táticas mercadológicas são mais eficazes, quando se adaptam às demandas do poder de consumo de cada grupo de clientes, não teria sido essa a decisão das grandes empresas americanas ao se dirigirem para o mercado internacional. O que poderia acarretar também neste novo patamar de negócios, certo nível de adaptação aos valores culturais, preferências de produto e modelos de compras, acabou sendo em grande parte desconsiderado. As grandes majors direcionaram seus negócios para um plano de internacionalização, no qual prevaleceu a aplicação de esforços de produção e de comercialização padronizados, consolidando programas de marketing global.

Não faltaram deliberações sobre os prováveis níveis de adaptação do composto elaborado por Jerome McCarthy às culturas locais. A opção por um mix de marketing estandardizado foi aferida por autores como Kotler e Armstrong (2004, p.519):

Algumas empresas que atuam no mercado global ficam preocupadas com o que consideram como adaptação excessiva que eleva os custos e dilui a força global da marca. O resultado é que muitas delas criaram as assim chamadas marcas globais - mais ou menos o mesmo produto vendido da mesma maneira a todos os consumidores do mundo.

Esses argumentos pareciam verdadeiros para a maioria dos empreendedores, pois um tipo de economia cultural e de consumo foi configurada segundo os padrões das empresas americanas em termos de produção, de comercialização e de estratégias promocionais e publicitárias. Os defensores da padronização global aceitavam adaptações somente no caso de as necessidades locais não poderem ser alteradas ou evitadas. Assim, o sistema produtivo da indústria americana manteve algum tipo de intercâmbio com as engrenagens produtivas e comerciais dos países em desenvolvimento, incluindo nesta barganha desde alterações de produto e serviço, até exaltações de tradições locais, em atitudes cada vez mais ecléticas e multiculturais.

Alguns exemplos são comentados por Kotler e Armstrong (2004). A Mattel, fabricante das bonecas Barbie, comercializou durante décadas a boneca padrão "made in USA" - branca, pernas compridas e seios grandes. No Japão, após pressão da Takara, licenciada da marca, a matriz aceitou investir mais, autorizando a fabricação de uma Barbie "made in Japan" com as características do biotipo Oriental, o que permitiu vender dois milhões de bonecas em dois anos. A Coca-Cola comercializa, praticamente, o mesmo refrigerante em todos os países e dirige sua publicidade de acordo com um portfólio de ingredientes comuns, elaborados para um tipo de apelo que transcenda às culturais nacionais. Contudo, a Coca tradicional é mais doce ou contém menos gás em alguns países. A matriz autoriza a criação de outras marcas para atender o gosto dos consumidores locais ou altera os canais de distribuição de acordo com os fatores de mercado e logística nos quais se encontram seus licenciados.

O impacto de uma administração majoritariamente centralizada e do derrame de produtos americanos, nos sistemas culturais e de consumo, até 1980 começa a se modificar, a partir da globalização e transnacionalização dos mercados. Garantidos pela fusão de empresas que potencializam um compartilhamento significativo de objetos físicos e culturais estrangeiros na economia mundial, produzidos por empresas asiáticas e europeias, o protagonismo americano dava pistas de que poderia ser repensado.

A hibridez entre a Administração universalista e o gerenciamento local pode ser um pano de fundo para buscar na Sociologia outras pistas teóricas. Em 1988, quando publicou A moderna tradição brasileira, o Sociólogo Renato Ortiz dedicou o último capítulo para discutir a transposição do "nacional popular" para uma rede de conexões internacionais, direcionando os produtos para uma caracterização menos identificada com os valores nacionais, fenômeno típico da globalização que ele denominou de circuito "internacional popular". O autor constatou que esse fenômeno ocorria por dois motivos interligados: o avanço tecnológico e o compartilhamento universal de objetos. Assim, pelas redes de tecnologia, as corporações transnacionais com seus produtos mundializados e suas marcas facilmente identificáveis se tornaram referências no espaço mundial, mediados pela cultura de consumo e a publicidade (ORTIZ, 2001).

Ortiz reafirmava que a maior parte das percepções construídas em fragmentos vindos de todas as partes teria sido possível com o advento da indústria cultural (cinema, música, publicidade) originadas ou operadas a partir das corporações americanas ou europeias, que teriam coberto todos os países, aproximando-os de uma cultura internacional (ORTIZ, 2001).

Sobre isso, Nestor Canclini (2006) analisa a globalização como um fenômeno de fracionamento social, cultural e econômico do Mundo e não como um processo de homogeneização cultural. As diferenças e desigualdades encontradas nas sociedades, no entendimento de Canclini, são rearticuladas, mas não inteiramente suprimidas por uma tendência imperialista ou totalizadora vinda dos EUA. As sociedades podem ser pressionadas a absorver valores e crenças globais e de todos os modos sucumbem a essas, mas essas diferenças ganham significados próprios e se reinventam em pertencimentos cada vez mais peculiares (CANCLINI, 2006).

Quando concluiu o livro Consumidores e cidadãos, Canclini analisava como as identidades se consolidavam cada vez mais em torno de ícones como Hollywood, Televisa ou MTV, cada vez menos em torno dos símbolos nacionais e mais como redes de consumidores. Anos mais tarde, em $A$ globalização imaginada (2003), ele identifica, por exemplo, que os mexicanos, que adentram a fronteira americana descobrem que a empresa que os contratará é coreana ou japonesa. O discurso da identidade corporativa da moderna empresa privada dos EUA precisava lidar com a nova 
realidade globalizada, a partir da qual não existiria um eixo majoritário original dos EUA ou da Europa, mas frações dos principais eixos produtivos mundiais arranjados de modo a sugerir uma "teia" transnacional, ao invés de uma linha de evolução capitaneada pela ideologia de negócios da América.

Um ponto discutido em destaque por Canclini (2006) é que em sua visão pós-moderna, a cultura é cada vez mais uma construção multinacional e cada vez menos "nacional". As regras de anos atrás estão sendo subvertidas pela industrialização globalizada dos meios de produção e comunicação, que organizam processos de interação funcional das atividades econômicas e culturais, de forma dispersa, com muitos centros cuja referência não é mais o território, no qual são fabricados os bens, mas a velocidade com que percorre o Mundo, quando de sua idealizaçãofabricação. Pode-se depreender, então, que não somente as identidades corporativas, mas as identidades nacionais a essas relacionadas estão se deslocando.

Veja-se um exemplo na indústria automobilística. Em 1998, a Chrysler se fundiu com a Daimler-Benz e, em 1999, a Ford anunciou que assumia a sueca Volvo, que seria novamente vendida, em 2010, para a Geely da China ${ }^{5}$. Em 2011, diante de dificuldades financeiras, a Ford descontinuou a marca Mercury sob a qual tinha direitos desde 1938 na América do Norte e Oriente Médio ${ }^{6}$. Ford e Chrysler conseguem manter a vinculação de suas identidades como corporações americanas, levando-se em conta estas aquisições e a dispersão de seus centros de fabricação, de comercialização e de publicidade?

As marcas Google, Apple ou Facebook carregam, em suas origens, o espírito nativo do empreendedorismo americano do Vale do Silício na Califórnia, mas não é crível admitir que seus negócios sejam admirados pela exclusividade do modelo de gestão americano a ser copiado. Essas corporações não geraram uma personal brand capaz de se transformar em emblema nacional como a Disney, Boeing ou alguma das famosas department stores (Sears, Macys, Saks), símbolos da inovação e da cultura de consumo americana. A natureza criativa e as condições do mercado interno americano foram a alavanca inicial dos negócios tradicionais, mas a partir dos anos 1980, as empresas se descolaram da identidade americana, para abraçar uma identidade transnacional global.

\section{Conclusão}

Parece inegável que as crenças na liberdade e igualdade, combinadas no ambiente empresarial com a constituição da sociedade anônima, tenham garantido à iniciativa privada nos EUA, uma boa dose de transcendência da cultura nacional para cumprir os alvos institucionais destas empresas. Com o propósito de impregnar as grandes corporações nascidas em solo americano, com o mesmo espírito empreendedor da Nação, foram direcionados por parte das empresas e dos setores governamentais, midiáticos e educacionais os recursos necessários para elaborar objetivos de comunicação afinados com essa sinergia entre a cultura nacional e a identidade corporativa das empresas.

A despeito do discurso que visava legitimar a unicidade cultural e a organização do trabalho corporativo, no interior de cada grande empresa dos EUA, os estudos sociológicos e antropológicos colocaram em xeque esse mecanismo impessoal, normatizado das corporações americanas, pensado pelos seus gestores. No entanto, não seria em algum movimento interno nascido dentro das próprias organizações que viria alguma contestação sobre as propostas para uma identidade de marketing global.

Apesar do impacto das forças propulsoras para uma estratégia global das multinacionais americanas, verificase que a partir da década de 1980, as ofertas vencedoras em escala global não se mostravam capazes de gerar vantagem competitiva com a mesma disciplina e esforço das décadas anteriores. $\mathrm{O}$ motor deste movimento restritivo foi a globalização, que acarretou desde então, um deslocamento das identidades nacionais firmemente estabelecidas e o consequente desprendimento da percepção da superioridade do modelo de gestão das corporações americanas. As empresas já não podiam ser associadas a seus países de origem e aos seus mitos de formação administrativa ou gerencial, mas à capacidade de oferecer respostas rápidas às demandas regionais, através de fusões e de integrações verticais ou horizontais, que sem abandonar a filosofia global de expansão, precisavam desintermediar seus centros de produção, marketing e comunicação. $\mathrm{O}$ custo desta iniciativa foi a perda da identidade corporativa ligada aos valores nacionais, que também empreendiam um deslocamento.

Os princípios ligados a este distanciamento dos valores nacionais estão associados com a ideia de que já não podiam ser encapsulados na Nação branca, protestante, anglosaxônica e europeia associados à formação original dos EUA e internalizados até meados do século XX. O país vem se transformando para caracterizar uma sociedade multiétnica e multicultural, que abriga negros, latinos, asiáticos e árabes de várias origens sociais e religiosas.

\section{Referências}

ANDERSON, B. Imagined Communities. Londres: Verso, 1983.

BOAS, F. Os objetivos da pesquisa antropológica, 1932. In: CASTRO, C. Antropologia Cultural. Rio de Janeiro: Jorge Zahar Editor, 2006. p. 87-109.

BOURDIEU, P. Questões de sociologia. São Paulo: Marco Zero, 1983.

CANCLINI, N.G. Consumidores e cidadãos. Rio de Janeiro: UFRJ, 2006.

CANCLINI, N.G. A Globalização imaginada. São Paulo: 
Iluminuras, 2003.

CUCHE, D. A noção de cultura nas ciências sociais. Bauru: Edusc, 2002.

DAVIDSON, J.W. Uma breve história dos Estados Unidos. São Paulo: L\&PM, 2016.

DRUCKER, P.F. The practice of Management. New York: Harper and Row [1954]

DURKHEIM, E. As formas elementares da vida religiosa. São Paulo: Paulus, 2001.

DURKHEIM, É.; MAUSS, M. Algumas formas primitivas de classificação. São Paulo: Perspectiva, 1990.

EKIRCH Jr. A.A. A democracia americana: teoria e prática. Rio de Janeiro: Zahar, 1965.

FOUCAULT, M. A ordem do discurso. São Paulo: Edições Loyola, 1996.

HALL, S. A identidade cultural na pós-modernidade. Rio de Janeiro: DP\&A, 2006.

HOFSTEDE, G.; BOND, M.H. The confucius connection: from cultural roots to economic growth. Organizational Dynamics, 1988.

KAUFMANN, J.-C. A invenção de si: uma teoria da identidade. Lisboa: Instituto Piaget, 2004.
KEYS, J.B.; MILLER, T.R. The Japanese management theory jungle. Amherst: Academy of Management Review, 1984.

KOTLER, P.; ARMSTRONG, G. Princípios de Marketing. São Paulo: Prentice Hall, 2004.

LÉVI-STRAUSS, C. Raça e História. São Paulo: Editora Vega, 2009.

MCCARTHY, E.J. Marketing Básico: uma visão gerencial. Rio de Janeiro: Zahar, 1976.

MEAD, G.H. Espiritu, persona y sociedad. México: Paydós, 1993.

ORTIZ, R. A moderna tradição brasileira. São Paulo: Brasiliense, 2001.

SAINSAULIEU, R. Sociologia da empresa: organização, cultura e desenvolvimento. Lisboa: Instituto Piaget, 1997.

SCHLESINGER Jr. A.M. Os ciclos da história americana. Rio de Janeiro: Civilização Brasileira, 1992.

SUGO, A.I.; VASCONCELLOS, H. Administração japonesa. Rev. Adm. Empres., v.30, n.4.. 1990. doi: https://doi.org/10.1590/ S0034-75901990000400010

TAYLOR, F.W. Princípios de Administração Científica. São Paulo: Atlas, 1990.

TUCKER, R. HENDRICKSON, D.C. Empire of Liberty: The Statecraft of Thomas Jefferson. Oxford University Press, 1992. 